\title{
Competition Under Diseconomies of Scale: The Role of Subcontracting and Single-sourcing Commitment
}

\author{
Lusheng Shao \\ Department of Management and Marketing, The University of Melbourne, VIC, Australia, 3010 \\ lusheng.shao@unimelb.edu.au
}

\begin{abstract}
This paper studies a supplier competition model in situations with flexible resources where suppliers face diseconomies of scale. Under such a situation, it is generally believed that a buyer may split an order across different suppliers; and even if the buyer chooses only one supplier, the winning supplier may subcontract part of the work to the others. Our results, however, show that the buyer always prefers to commit to single-sourcing prior to running a procurement auction. This is because such commitment eliminates the 'assurance' of getting a positive order from the buyer, thus intensifying supplier competition. We also find that subcontracting may be beneficial (detrimental) to the buyer if the subcontract is determined by the winning (losing) supplier of the bidding game. Finally, we show that, for the case with linear costs, the buyer is always better off when subcontracting is considered.
\end{abstract}

Key words: Subcontracting; split contracts; diseconomies of scale; commitment; supplier competition

\section{Introduction}

Advances in information and communication technology have opened new channels for firms' procurement functions. A growing number of companies are rethinking their sourcing strategies and switching from bilateral negotiation to competitive bidding, because they can now easily access different suppliers and maintain reasonable competition (Tunca and Wu 2009). For example, Sun Microsystems awarded almost $70 \%$ of its annual procurement contracts using auctions, worth US\$2.7 billion (Carbone 2007). More recently, Maersk is turning to cloud computing services to make better procurement decisions for its global shipping and oil businesses, and $89 \%$ of its procurement business was awarded by using e-auctions in 2014 (Norton 2015).

In this procurement regime, an understanding of supplier bidding behavior will help buying firms design better sourcing rules, and hence improve procurement performance. A typical tradeoff suppliers face is to keep their prices competitive enough (in order to win the bidding game) and meanwhile make as much profit as possible when winning the game. Such a trade-off is even more challenging when supplier costs exhibit diseconomies of scale because it involves sophisticated bidding formats rather than prices only. Diseconomies of scale arise in settings with multiple 
flexible resources that can be used. For example, when a manufacturer owns multiple production plants, the production cost at each plant may be different due to a combination of factors, such as geographical locations, employee wages, and material costs. In this case, the manufacturer will produce for costumer orders by using low-cost plants first; thus it faces increasing marginal costs as the production quantity increases. In the contract cleaning industry, large contractors usually work with a number of other contractors or individual traders/cleaners (IBIS 2014). Since the prime contractor uses the cheapest service first, it will naturally face increasing marginal cleaning costs. Disconomies of scale also occur when there are steep increases in costs with addition of a new shift, technological and productivity changes, labor slowdowns, etc. (Kesavan and Mani 2015). In particular, in labor-intensive industries such as contract cleaning, the unit hiring cost increases in the number of workers because of the increasing difficulty of finding workers.

In bidding situations with diseconomies of scale, it may be cost-effective for a buyer to split an order across different suppliers (Burke et al. 2007, Bernstein et al. 2013). Even if the buyer awards its entire order to a single supplier, the winning supplier may subcontract part of the work to the others later. Indeed, subcontracting has become a prominent business practice in a broad range of industries such as contract manufacturing and contract cleaning services (Atamturk and Hochbaum 2001). Different from outsourcing, subcontracting typically refers to the situation in which a prime contractor procures an item or service that the contractor is normally capable of producing using its own facilities (Van Mieghem 1999). One can think of outsourcing as the special case of subcontracting in which the contractor has no in-house facilities and depends on the subcontractor for the entire product volume.

In general, subcontracting is undertaken based on the need for additional production or service. A prime contractor may depend on a subcontractor to meet the balance of the order since otherwise higher costs will be incurred (Van Liemt 2007). For example, in the Bangladesh garment industry, if factories miss a shipping deadline, they have to rush the shipment by airfreight, at their own expense, or give buyers a 5\% discount as a penalty (Lahiri and Passariello 2013). Large garment factories in Bangladesh even take orders based on subcontracting capacity. According to the managing director of the Bangladesh office of Synergies Worldwide, “... [garment factories] may have a two-million capacity and they will take orders for four-million ..." (Lahiri and Passariello 2013). Overall, subcontracting is driven by some form of diseconomies of scale in the sense that contractors face higher marginal costs when a customer's order becomes larger.

Although suppliers may benefit from subcontracting, it remains unclear whether subcontracting also benefits buyers. In practice, some firms allow subcontracting for their cleaning jobs, such as Westfield Group, while others do not, such as Mirvac Group (Wynhausen 2008). Understanding the impact of subcontracting is important for buyers because it allows them to design better 
sourcing rules. In addition, with multiple units to buy, a firm's critical decision is whether to split an order among multiple suppliers (multi-sourcing) or award the entire order to a single supplier (single-sourcing) (Elmaghraby 2000). Intuitively, the buyer's choice between single-sourcing and multi-sourcing may be affected by which strategy benefits the supply chain as a whole, which in turn depends on suppliers' cost structure. When supplier costs exhibit diseconomies of scale, multi-sourcing may generate more values to a supply chain; in this case, the buyer may be able to capture a share of surpluses. The existing research on sourcing strategies has been focused on expost decisions for buyers given exogenous supply contracts (Talluri and Narasimhan 2004, Talluri et al. 2013). It is then interesting to investigate how the pre-commitment on sourcing strategies affects competition between suppliers and the buyer's procurement performance.

Motivated by the above observations, this paper studies a supplier competition model where supplier costs exhibit diseconomies of scale, with a focus on the impact of single-sourcing commitment and subcontracting. Specifically, we ask the following questions: (i) Does a buyer benefit from making a commitment to sourcing from only one supplier? (ii) If so, how does subsequent subcontracting between suppliers affect their competitive behaviors, and the buyer's profit? To answer these questions, we consider two procurement scenarios: (i) single-sourcing commitment, in which the buyer commits to purchasing from only one supplier, but suppliers have the option to subcontract with each other subsequently; and (ii) order splitting, in which the buyer does not make a single-sourcing commitment and thus may split an order. The goal is to obtain a better understanding of how those sourcing arrangements affect buyer procurement performance. To this end, we first characterize the equilibrium for suppliers under each scenario. Then we compare these two scenarios to examine whether the buyer has incentives to make a single-sourcing commitment before running a bidding process. Under the situation with single-sourcing commitment, we also examine the benchmark case where subcontracting is not considered. The comparison between the case with subcontracting and that without subcontracting allows us to investigate the effect of subcontracting on supplier competition in the bidding game.

The main results of this paper are summarized as follows. First, in the situation with singlesourcing commitment, we model subcontracting negotiation between competing suppliers within the Stackelberg framework, in which either the winning or losing supplier offers the subcontract to the other. We find that, when the winning supplier determines the subcontract (and hence has more bargaining power in subcontracting), the buyer will make a higher profit whereas each supplier makes a lower profit than when the losing supplier determines the subcontract. The intuition of this prisoner's dilemma result is that the winning supplier's higher bargaining power translates to a greater profit-making opportunity in subcontracting. This makes winning the bidding game even more lucrative, which then leads to more fierce competition between suppliers. Consequently, 
the buyer (each supplier) becomes better (worse) off in equilibrium. Contrary to the conventional wisdom that subcontracting softens the competition between suppliers (Marion 2015), our results show that subcontracting may benefit the buyer if the subcontract is designed by the winning supplier of the bidding game. This highlights the important impact of bargaining power split in subcontracting negotiation on buyer procurement performance.

Second, in the situation without commitment, we show that in equilibrium suppliers selfcoordinate with each other to achieve the supply chain optimal outcome. Each supplier makes a profit equal to its marginal contribution to the supply chain as a whole, and the buyer takes the remaining profit. This mirrors a result by Cachon and Kok (2010) who show that when manufacturers each submit a two-part tariff contract to a common retailer, the supply chain will be coordinated in equilibrium. Our model extends their model in two ways: first we consider scale diseconomies; second suppliers in our model each submit a supply function in light of the nonlinear cost. Here a supply function specifies different payments for different quantities, and it covers two-part tariff contracts as a special case.

Third, our analysis shows that the buyer is better off making a single-sourcing commitment, whether or not subcontracting is considered. The result is mainly driven by the intensified competition due to the buyer's single-sourcing commitment. Without commitment, suppliers may feel a sense of security that they can get some business from the buyer and hence bid less aggressively. Consequently, despite the fact that splitting an order generates a higher supply chain profit, the buyer prefers to commit to single-sourcing.

The main contributions of this paper are two-fold. First, many operations management models assume that firms have linear total costs. To our knowledge, the strategic interaction among suppliers facing scale diseconomies has not been well explored in the operations management literature. This paper attempts to fill this gap by incorporating subcontracting and commitment into the supplier competition model. We find some contrasting results between the case with diseconomies of scale and that with linear costs, highlighting the importance of studying diseconomies of scale. Second, the model enables us to investigate how single-sourcing commitment and subcontracting affect the competition dynamics for suppliers, while providing valuable guidance on firms' procurement practices. An important insight is that buyers may commit to single-sourcing when running a bidding process. In addition, given the tight tie between subcontracting and supplier bidding, it is important for buying firms to gain an understanding of the subcontracting market in which their suppliers might participate.

The remainder of this paper is organized as follows: We review the relevant literature in Section 2 and set up the model in Section 3. Section 4 and Section 5 study the two procurement scenarios, respectively. Section 6 compares these scenarios based on each player's profit. In Section 7 we 
extend our baseline model by considering linear costs, and discuss the managerial insights. For convenience, we summarize the key symbols in Table 1 which can be found at the end of this paper. All the proofs are relegated to an online appendix.

\section{Literature Review}

This paper examines supplier contract competition under diseconomies of scale. There is a rich literature on supply chain contracting; see Lariviere (1999) and Cachon (2003) for excellent literature reviews. This literature focuses on one-to-one or one-to-many supply chains in which supplier costs are linear (Cachon 2003). Several papers have begun to study supply contract competition. Babich et al. (2007) study a supplier competition model where a buyer purchases a homogeneous product from multiple unreliable suppliers. Wu and Kleindorfer (2005) and Martínez-de Albéniz and Simchi-Levi (2009) examine supplier competition in a supply option market. Cachon and Kok (2010) consider a setting in which two manufacturers sell differentiated products to a retailer, and examine how different contract forms affect competition between manufacturers. Gallego and Talebian (2014) examine competing manufacturers' decisions on commissions and sales targets. The current paper contributes to this literature by examining a situation in which suppliers face diseconomies of scale. In addition, we incorporate subcontracting and single-sourcing commitment into the supplier competition model, which allows evaluation of their impacts on supplier bidding behaviors and supply chain performance.

In the scenario of single-sourcing commitment with subcontracting, the game involves both competition (i.e., supplier bidding) and cooperation (i.e., subcontracting). The co-existence of competition and cooperation has been considered by operations management researchers; see Nagarajan and Sosic (2008) for a literature review. Notably, Nagarajan and Sosic (2007) study strategic alliance formation among firms who sell substitutable products in a common market. The authors consider both alliance formation, and price and inventory competition. In development-intensive supply chains, Usta et al. (2015) study how a powerful buyer can use supplier cooperation as a lever to improve profits by considering low price commitment and diversified sourcing through egalitarian allocations. Similar arrangements also occur in the inventory transshipment literature where the focus is on understanding newsvendors' ordering decisions (Rudi et al. 2001, Zhao et al. 2005, Li et al. 2016). Our paper differs from this literature in that: (a) the cooperation in our model is in the form of subcontracting, which is different from the strategic alliance formation in cooperative games; (b) we model supplier cooperation as an endogenous decision (in the subcontracting game), whereas the supplier cooperation in existing models is exogenous in the sense that there is no strategic interaction between suppliers.

Subcontracting alone has received some attention from the economics and operations management communities. Kamien et al. (1989) examine a duopoly competition model where symmetric 
firms make production and subcontracting decisions. Van Mieghem (1999) studies an investment game in which manufacturers first decide on their capacity investment levels, and then choose production and sales quantities with the consideration of subcontracting. Marion (2015) empirically investigates the effect of subcontracting on firm bidding strategies in California highway construction auctions. The author finds that, while subcontracting may improve productivity efficiency, it softens the horizontal subcontractors' bidding strategies. This literature does not consider supply chain settings, and hence does not involve the buyer's optimization problem. In contrast, we study a many-to-one supply chain where the buyer is a profit maximizer. In addition to the scenario of single-sourcing commitment, we also consider the order splitting scenario in which the buyer does not commit to single-sourcing. By comparing these scenarios, we are able to reveal insights into the value of such commitment for the buyer.

The comparison between the two procurement scenarios resembles that between delegation and control mechanisms in the principal-agent literature, in which a buyer purchases multiple products that are each produced by different privately informed suppliers. In the control case (similar to this study's order splitting), the buyer purchases from each supplier directly, while in the delegation case (similar to this study's single-sourcing commitment), the buyer purchases only from a primary supplier who is delegated to purchase the other products. The main result is that the buyer prefers the control case because there is a cascading effect of information rent in the delegation case (Mookherjee 2006). Our model differs from the above papers in three aspects. First, this literature examines the buyer's optimal procurement mechanism, whereas our paper studies a Stackelberg game with suppliers being the leaders. Second, in our commitment model, the competitors in the bidding game can be collaborators in the subcontracting game, a feature missing in mechanism design models. Third, our result is in sharp contrast with theirs - we find that single-sourcing commitment outperforms order splitting from the buyer's perspective.

Finally, the paper is loosely related to the literature on multi-unit procurement auctions; see Elmaghraby (2000) for a collection of papers on supplier competition and procurement auctions. In a setting where a buyer purchases multiple units of an item, various auction formats can be applied, such as split-award auction (Anton and Yao 1989, 1992), multi-unit auction (Ausubel and Milgrom 2006), and menu auction (Bernheim and Whinston 1986). With a fixed purchase quantity, this literature focuses on price discovery and order allocation. With an endogenous amount, Chen (2007) proposes a supply contract auction in which the buyer first designs a quantity-payment schedule and then auctions off this contract by inviting each supplier to bid a lump-sum fee. Dasgupta and Spulber (1989) study a similar problem and develop a quantity auction in which each supplier bids a supply quantity instead of a lump-sum fee. Contrasting with this literature, our intention is not to design an optimal auction mechanism for the buyer. Instead, the buyer - as a Stackelberg follower-makes ordering decisions after receiving supplier bids. 


\section{Model Setup}

We consider a supply chain with two suppliers ("he") and one buyer ("she"), where the buyer purchases a homogeneous product or service from these two suppliers. For easy reference, we will focus on a product supply chain. Each player is risk neutral and maximizes their own profits. The buyer has an expected revenue of $R(q)$ if she purchases $q$ units of the product. We assume $R(q)$ is a finite, increasing, and concave function of $q \geq 0$, and $R(0)=0$. This revenue function covers the newsvendor setting as a special case. Suppose demand $D$ follows a distribution with cdf $F(d)$. With the unit selling price $r$ and zero penalty for unmet demand and zero salvage costs for excessive orders, the revenue function is given by $R(q)=r \mathbb{E}[\min (D, q)]=r\left(q-\int_{0}^{q} F(\tau) d \tau\right)$, which can be readily checked to be increasing and concave with $R(0)=0$.

Each supplier $i$ 's cost is denoted by $C_{i}(q)$, where $i=1,2$. To model diseconomies of scale, we assume the cost function $C_{i}(q)$ is twice differentiable, increasing and strictly convex, i.e., $C_{i}^{\prime}(q)>0$ and $C_{i}^{\prime \prime}(q)>0, \forall q>0$. Also, $C_{i}(0)=0$. The convex cost functions have been commonly used to capture scale diseconomies in operations management; see, for example, Majumder and Srinivasan (2008) and Ha et al. (2011). The diseconomies of scale are also supported by many empirical evidences in industries where firms use the cheapest resource first, then the second cheapest, and so forth (Kamien et al. 1989, Baldick et al. 2004, Mollick 2004).

To address our research questions, we consider two procurement scenarios: (i) single-sourcing commitment, in which the buyer commits to purchasing from only one supplier before the suppliers submit their bids and the winning supplier can subsequently subcontract with the losing supplier; and (ii) order splitting, in which the buyer does not make any commitment regarding the number of winners in the bidding game. Single-sourcing commitment involves supplier bidding in the first stage and subcontracting negotiation in the second stage. We model the subcontracting game in the Stackelberg framework where either the winning or losing supplier offers a subcontract to the other.

In a situation with order splitting, the timeline of the game is as follows: First, each supplier submits a function bid to the buyer. Second, the buyer decides how much to purchase from each supplier. Third, the suppliers with positive orders begin production and deliver the product to the buyer. Finally, the buyer sells the product to the market and collects revenue from consumers. In a situation with single-sourcing commitment, the timeline differs mainly in that the winning supplier may subcontract with the losing supplier subsequently. See Figure 1 for the detailed sequence of events for each scenario.

In our model, the suppliers are Stackelberg leaders and the buyer is a follower. The suppliers compete for the buyer's procurement contract. We consider a full information setting where suppliers are aware of each other's cost but the buyer does not know the supplier costs. This assumption fits 


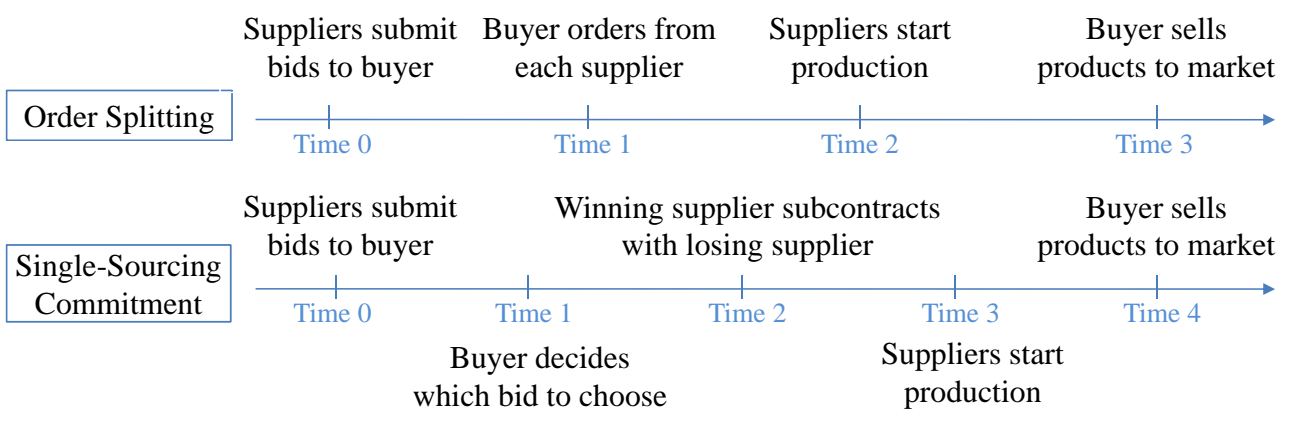

Figure 1 The timeline under each scenario

situations where the production technologies and business environments are relatively transparent. Similar game settings have been commonly used in operations management; see, e.g., Cachon and Kok (2010) and Martínez-de Albéniz and Simchi-Levi (2009).

As a preliminary step, we now examine the integrated supply chain problems that are equivalent to the buyer's problems when suppliers charge only their costs. We choose the order quantity from each supplier to maximize the supply chain profit:

$$
\max \left\{\Pi\left(q_{1}, q_{2}\right)=R\left(q_{1}+q_{2}\right)-C_{1}\left(q_{1}\right)-C_{2}\left(q_{2}\right): q_{1}, q_{2} \geq 0\right\}
$$

To avoid triviality, we assume that there is an interior solution for the above problem, which implies that splitting an order is optimal from the supply chain's perspective. We can show that $\Pi$ is jointly concave in $q_{1}$ and $q_{2}$; thus the optimal interior solution $\left(\bar{q}_{1}, \bar{q}_{2}\right)$ is characterized by the following conditions:

$$
R^{\prime}\left(\bar{q}_{1}+\bar{q}_{2}\right)=C_{1}^{\prime}\left(\bar{q}_{1}\right)=C_{2}^{\prime}\left(\bar{q}_{2}\right) .
$$

Let $\bar{Q}=\bar{q}_{1}+\bar{q}_{2}$ be the supply chain optimal total quantity and $\Pi=\Pi\left(\bar{q}_{1}, \bar{q}_{2}\right)$ be the supply chain optimal profit. Now consider the case where supplier $i$ is the sole supplier where $i=1,2$. If the buyer purchases from supplier $i$ only, then the supply chain problem is $\max \left\{\Pi_{i}(q)=R(q)-C_{i}(q): q \geq 0\right\}$. Since $\Pi_{i}(q)$ is concave in $q$, the optimal solution $\bar{Q}_{i}$ can be found from the condition:

$$
R^{\prime}\left(\bar{Q}_{i}\right)=C_{i}^{\prime}\left(\bar{Q}_{i}\right) \text { for } i=1,2 \text {. }
$$

Define $\Pi_{i}$ as the supply chain optimal profit when supplier $i$ is the sole supplier, so $\Pi_{i}=\Pi_{i}\left(\bar{Q}_{i}\right)$. Note that we have $\Pi>\max \left(\Pi_{1}, \Pi_{2}\right)$, and $\bar{Q}>\bar{Q}_{i}>\bar{q}_{i}$ where $i=1,2$. We refer to $\Pi-\Pi_{j}$ as supplier $i$ 's marginal contribution to the supply chain system, where $j=3-i$.

Throughout the paper we use the following example to illustrate the equilibrium strategies and payoffs for each scenario. 
EXAmple 1. Suppose the revenue function is $R(q)=q-q^{2} / 2$, and the cost functions are $C_{1}(q)=$ $q^{2} / 2$ and $C_{2}(q)=q^{2}$. It can be readily shown that the supply chain optimal solution is $\left(\bar{q}_{1}, \bar{q}_{2}\right)=$ $(2 / 5,1 / 5)$, the total quantity is $\bar{Q}=3 / 5$, and the supply chain optimal profit is $\Pi=3 / 10$. If supplier 1 is the sole supplier, the optimal quantity is $\bar{Q}_{1}=1 / 2$, and the single-sourcing supply chain optimal profit is $\Pi_{1}=1 / 4$. Similarly, if supplier 2 is the sole supplier, the optimal quantity is $\bar{Q}_{2}=1 / 3$, and the single-sourcing supply chain optimal profit is $\Pi_{2}=1 / 6$.

In the following sections, we characterize the equilibria for suppliers under both single-sourcing commitment and order splitting. Then we make a comparison between them.

\section{Single-Sourcing Commitment}

Under the scenario of single-sourcing commitment, the buyer commits to purchasing from only one supplier before suppliers submit their bids, so only one supplier will be chosen by the buyer. Each supplier $i$ offers a payment-quantity bid $\left(T_{i}, Q_{i}\right)$ to the buyer, where $i=1,2$. If the buyer selects the bid $\left(T_{i}, Q_{i}\right)$, then her expected profit is given by,

$$
\pi_{B}\left(T_{i}, Q_{i}\right)=R\left(Q_{i}\right)-T_{i}
$$

The buyer chooses the bid that gives her a larger profit. If the two bids give the buyer the same profit, we need to specify a tie-breaking rule. Because suppliers engage in an all-or-nothing competition in the bidding game, randomly selecting a supplier in case of a tie leads to discontinuous payoff functions. The same issue also occurs in the Bertrand competition model with differentiated costs. It is a well-known result that this type of discontinuous game fails to have a pure strategy Nash equilibrium (Tirole 1988). One of the ways to avoid this issue in the literature is to assume that ties are broken in favor of the low-cost supplier (Tirole 1988, Simon and Zame 1990). We follow suit by assuming that, in case of a tie, the buyer prefers the supplier who gives a higher supply chain profit. This reflects the fact that the supplier with cost advantage can always submit a bid that gives the buyer a slightly higher profit so that he will win the game. If the supply chain profits for both suppliers are identical (i.e., both suppliers are equally cost-efficient), the buyer will randomly select a supplier.

\subsection{Competition without subcontracting}

To examine whether the buyer benefits from subcontracting, we first look at the benchmark case in which subcontracting is not considered. Given supplier $j$ 's bid $\left(T_{j}, Q_{j}\right)$, we look at supplier $i$ 's best response in choosing $\left(T_{i}, Q_{i}\right)$, where $i=1,2$ and $j=3-i$. If supplier $i$ wins, i.e., when $\pi_{B}\left(T_{i}, Q_{i}\right)>\pi_{B}\left(T_{j}, Q_{j}\right)$, his profit is given by $\pi_{i}\left(T_{i}, Q_{i}\right)=T_{i}-C_{i}\left(Q_{i}\right)$. If supplier $i$ loses, i.e., when $\pi_{B}\left(T_{i}, Q_{i}\right)<\pi_{B}\left(T_{j}, Q_{j}\right)$, his profit will be zero, where the function $\pi_{B}$ is given in (3). In case of a tie, the buyer will break ties in favor of the low-cost supplier. 
Each supplier $i$ maximizes his own profit by choosing an optimal bid. We now characterize the equilibrium in Proposition 1.

Proposition 1 (Equilibrium without subcontracting). Suppose subcontracting is not considered, then:

(a) There exists a unique Nash equilibrium $\left\{\left(T_{1}^{n}, Q_{1}^{n}\right),\left(T_{2}^{n}, Q_{2}^{n}\right)\right\}$ where, for $i=1,2$ and $j=3-i$, $Q_{i}^{n}=\bar{Q}_{i}$ and $T_{i}^{n}=C_{i}\left(\bar{Q}_{i}\right)+\max \left(0, \Pi_{i}-\Pi_{j}\right) ;$

(b) in equilibrium, supplier i's profit is $\pi_{i}^{n}=\max \left(0, \Pi_{i}-\Pi_{j}\right)$, the buyer's profit is $\pi_{B}^{n}=$ $\min \left(\Pi_{i}, \Pi_{j}\right)$, and the supply chain profit is $\Pi^{n}=\max \left(\Pi_{i}, \Pi_{j}\right)$.

Proposition 1 shows that each supplier $i$ bids a quantity $Q_{i}^{n}=\bar{Q}_{i}$, meaning that each supplier submits a bid with the quantity maximizing the supply chain profit when he is the sole supplier. This is because, by choosing the quantity $\bar{Q}_{i}$, supplier $i$ is in the best position to compete with the rivalry supplier $j$.

Part (b) of the proposition reveals that, if $\Pi_{i}=\Pi_{j}$, the buyer randomly selects a supplier and both suppliers make zero profits; if $\Pi_{i}>\Pi_{j}$, according to our tie-breaking rule, the buyer will select supplier $i$. In equilibrium supplier $i$ makes a profit of $\Pi_{i}-\Pi_{j}$, supplier $j$ makes zero profits, and the buyer's profit is $\Pi_{j}$. This model can be thought of as an extension of Bertrand duopoly model into the supply chain setting, where each supplier offers a price as well as a quantity. The above equilibrium outcome echoes the Bertrand competition outcome where the undercutting behavior occurs (Tirole 1988).

EXAMPLE 2. We illustrate the above equilibrium using the run-through example given in Example 1. Based on Proposition 1, the equilibrium strategies are: $\left(T_{1}^{n}, Q_{1}^{n}\right)=(5 / 24,1 / 2)$ and $\left(T_{2}^{n}, Q_{2}^{n}\right)=$ $(1 / 9,1 / 3)$. In equilibrium the buyer will select supplier 1 , and the profit split is: $\pi_{1}^{n}=1 / 12, \pi_{2}^{n}=0$, and $\pi_{B}^{n}=1 / 6$. The supply chain profit is $\Pi^{n}=1 / 4$.

\subsection{Competition with subcontracting}

In the presence of subcontracting, the game involves two stages: In the first stage, suppliers compete by offering quantity-payment bids and the buyer selects the bid that gives her a larger profit; and in the second stage, subcontracting may occur between the winning supplier and the losing supplier of the bidding game. To model the subcontracting negotiation, we adopt the Stackelberg framework, which has been used extensively in the operations management literature. Depending on which player is the Stackelberg leader, we consider two cases: (1) the winning supplier is the leader, and (2) the losing supplier is the leader. In the subcontracting game, the leader offers a take-it-or-leave-it subcontract to the follower, who then decides whether or not to accept the subcontract. 
We solve this multi-stage game by following the standard backward induction approach: we begin by examining the subcontracting game and then analyze the bidding game. Note that at the time of subcontracting the buyer has decided which supplier to select. Without loss of generality, suppose supplier $k$ wins the bidding game where $k \in\{1,2\}$, so the winning bid is $\left(T_{k}, Q_{k}\right)$. In the following analysis of subcontracting game, we shall use $m=3-k$ to denote the losing supplier of the bidding game. Given the winning bid $\left(T_{k}, Q_{k}\right)$ and the subcontracting amount $q$, define the total gain from subcontracting as follows:

$$
\Delta_{k}\left(q ; Q_{k}\right)=C_{k}\left(Q_{k}\right)-C_{k}\left(Q_{k}-q\right)-C_{m}(q)
$$

which equals the difference in costs when subcontracting occurs.

4.2.1. Winning supplier as the leader In this case, the winning supplier $k$ designs a subcontract $\left(t_{m}, q_{m}\right)$ and offers it to the losing supplier $m$, where $m=3-k$. Here we use subscript $m$ for the subcontract to indicate that it is supplier $m$ that receives payment $t_{m}$ for producing $q_{m}$ units of the product. Supplier $k$ 's subcontracting problem is formulated as follows,

$$
\max \left\{\pi_{k}=T_{k}-C_{k}\left(Q_{k}-q_{m}\right)-t_{m}: 0 \leq q_{m} \leq Q_{k}, t_{m}-C_{m}\left(q_{m}\right) \geq 0\right\}
$$

where the constraint $t_{m}-C_{m}\left(q_{m}\right) \geq 0$ states that the losing supplier $m$ cannot make less profit than his reservation profit, which is normalized to zero. Since the objective function $\pi_{k}$ decreases in $t_{m}$, the constraint must be binding for the optimal solution. Thus, the above problem reduces to, $\max \left\{\pi_{k}=T_{k}-C_{k}\left(Q_{k}-q_{m}\right)-C_{m}\left(q_{m}\right): 0 \leq q_{m} \leq Q_{k}\right\}$. It is straightforward to show that $\pi_{k}$ is concave in $q_{m}$. Therefore, the optimal subcontracting quantity, denoted by $\hat{q}_{m}$, can be obtained by solving the first order condition:

$$
C_{k}^{\prime}\left(Q_{k}-\hat{q}_{m}\right)=C_{m}^{\prime}\left(\hat{q}_{m}\right)
$$

The above equation shows that given the total production quantity $Q_{k}$, it is optimal for supplier $k$ to subcontract $\hat{q}_{m}$ units to supplier $m$ and produce $Q_{k}-\hat{q}_{m}$ units himself. We note that $\hat{q}_{m}$ also maximizes the total gain from subcontracting. That is, $\hat{q}_{m}$ is a maximizer of $\Delta_{k}\left(q ; Q_{k}\right)$ for an given $Q_{k}$.

The optimal payment $\hat{t}_{m}$ can be obtained from the binding constraint, i.e., $\hat{t}_{m}=C_{m}\left(\hat{q}_{m}\right)$. In a nutshell, the optimal subcontract $\left(\hat{t}_{m}, \hat{q}_{m}\right)$ is obtained by solving equation (5) and equation $\hat{t}_{m}=C_{m}\left(\hat{q}_{m}\right)$. As a result, the losing supplier makes zero profits from subcontracting, while the winning supplier takes all the gains from subcontracting, which is given by $\Delta_{k}\left(\hat{q}_{m} ; Q_{k}\right)$.

Having examined the subcontracting game, we are now ready to analyze the suppliers' bidding problem, with each supplier anticipating the second stage's subcontracting decision. Here, we use the subscripts $i$ and $j$ for supplier indices to distinguish from those in the analysis of subcontracting 
game, where $i=1,2$ and $j=3-i$. Each supplier $i$ submits a bidding contract $\left(T_{i}, Q_{i}\right)$. The buyer's profit of choosing $\left(T_{i}, Q_{i}\right)$ is given by $\pi_{B}\left(T_{i}, Q_{i}\right)=R\left(Q_{i}\right)-T_{i}$, which is the same as (3).

By offering the contract $\left(T_{i}, Q_{i}\right)$, supplier $i$ may win, lose, or there is a tie for the buyer's decision. Specifically, if $\pi_{B}\left(T_{i}, Q_{i}\right)>\pi_{B}\left(T_{j}, Q_{j}\right)$, then supplier $i$ wins the bidding game, and makes a profit of $T_{i}-C_{i}\left(Q_{i}-\hat{q}_{j}\right)-C_{j}\left(\hat{q}_{j}\right)$. Note that this profit includes the gains from both subcontracting and bidding. If $\pi_{B}\left(T_{i}, Q_{i}\right)<\pi_{B}\left(T_{j}, Q_{j}\right)$, then supplier $i$ loses, and makes a profit of 0 . If there is a tie, the buyer will choose the supplier that gives a higher supply chain profit.

The next step is to solve the best response problem for each supplier, and then derive the Nash equilibrium for suppliers. The following proposition summarizes the equilibrium outcomes.

Proposition 2 (Equilibrium with subcontracting). Suppose the winning supplier determines the subcontract, then:

(a) There exists a unique subgame perfect Nash equilibrium $\left\{\left(Q_{1}^{w}, T_{1}^{w}, \hat{q}_{2}^{w}, \hat{t}_{2}^{w}\right),\left(Q_{2}^{w}, T_{2}^{w}, \hat{q}_{1}^{w}, \hat{t}_{1}^{w}\right)\right\}$ where, for $i=1,2, j=3-i, Q_{i}^{w}=\bar{Q}, \hat{q}_{j}^{w}=\bar{q}_{j}, T_{i}^{w}=C_{i}\left(\bar{q}_{i}\right)+C_{j}\left(\bar{q}_{j}\right)$, and $\hat{t}_{j}^{w}=C_{j}\left(\bar{q}_{j}\right)$.

(b) in equilibrium, each supplier $i$ 's profit is $\pi_{i}^{w}=0$, the buyer's profit is $\pi_{B}^{w}=\Pi$, and the supply chain profit is $\Pi^{w}=\Pi$.

Proposition 2 shows that, if the subcontract is determined by the winning supplier, then both suppliers submit the same bid to the buyer in the bidding game. That is, each supplier bids the same quantity, $Q_{1}^{w}=Q_{2}^{w}=\bar{Q}$, and charges the same amount, $T_{1}^{w}=T_{2}^{w}=C_{1}\left(\bar{q}_{1}\right)+C_{2}\left(\bar{q}_{2}\right)$. This suggests that the existence of subcontracting smooths out the asymmetry in supplier costs, and leads to a head-to-head competition. We note that the bidding quantity $\bar{Q}$ is the supply chain optimal total quantity, which is greater than the bidding quantity when subcontracting does not occur, i.e., $Q_{i}^{w}>\bar{Q}_{i}^{n}$ for $i=1,2$.

Another observation from the proposition is that, in equilibrium the buyer randomly selects a supplier as the winning supplier. If supplier $i$ is selected by the buyer, he will subcontract $\bar{q}_{j}$ to supplier $j$. Each supplier makes zero profits, and the buyer takes all the supply chain optimal profits. The intuition of this result is that: The subcontracting option makes winning the bidding game more profitable, because they can reap all the gains from subcontracting. Therefore, suppliers bid more aggressively, anticipating the large gain from subcontracting once they win the bidding game.

Example 3. We use Example 1 to illustrate the equilibrium for suppliers. Proposition 2 shows that the equilibrium strategies are symmetric, which are given by $\left(T_{1}^{w}, Q_{1}^{w}\right)=\left(T_{2}^{w}, Q_{2}^{w}\right)=$ $(3 / 25,3 / 5)$. In equilibrium the buyer will randomly select a supplier, say supplier 1 . Then supplier 1 offers a subcontract $\left(\hat{t}_{2}^{w}, \hat{q}_{2}^{w}\right)=(1 / 25,1 / 5)$ to supplier 2 . As a result, supplier 1 produces $2 / 5$ units of the product and supplier 2 produces $1 / 5$ units. The equilibrium profit split is: $\pi_{1}^{w}=\pi_{2}^{w}=0$, and $\pi_{B}^{w}=3 / 10$. The supply chain profit is $\Pi^{w}=3 / 10$. 
4.2.2. Losing supplier as the leader In this case, the losing supplier $m$ designs a subcontract $\left(t_{m}, q_{m}\right)$ and offers it to the winning supplier $k$. Supplier $m$ 's subcontracting problem is to maximize his profit by choosing the subcontract $\left(t_{m}, q_{m}\right)$ :

$$
\max \left\{\pi_{m}=t_{m}-C_{m}\left(q_{m}\right): 0 \leq q_{m} \leq Q_{k}, T_{k}-C_{k}\left(Q_{k}-q_{m}\right)-t_{m} \geq T_{k}-C_{k}\left(Q_{k}\right)\right\}
$$

where the constraint states that the winning supplier $k$ has to make as much profit as he would make without subcontracting. Again, the constraint must be binding. The losing supplier $m$ 's problem reduces to, $\max \left\{\pi_{m}=C_{k}\left(Q_{k}\right)-C_{k}\left(Q_{k}-q_{m}\right)-C_{m}\left(q_{m}\right): 0 \leq q_{m} \leq Q_{k}\right\}$. The optimal subcontracting quantity, $\hat{q}_{m}$, is obtained by solving the equation, $C_{k}^{\prime}\left(Q_{k}-\hat{q}_{m}\right)=C_{m}^{\prime}\left(\hat{q}_{m}\right)$. Note that this is the same as (5). This shows that, regardless of which supplier determines the subcontract, the total gain will be maximized. The optimal payment $\hat{t}_{m}$ is determined by the binding constraint, so we have $\hat{t}_{m}=C_{k}\left(Q_{k}\right)-C_{k}\left(Q_{k}-\hat{q}_{m}\right)$. In this case, the winning supplier receives zero profits from subcontracting, while the losing supplier takes all the gains from subcontracting, which is given by $\Delta_{k}\left(\hat{q}_{m} ; Q_{k}\right)$.

We now examine the first stage's supplier bidding problem. Given supplier $j$ 's bid $\left(T_{j}, Q_{j}\right)$, supplier $i$ 's problem is to maximize his profit by choosing $\left(T_{i}, Q_{i}\right)$. If $\pi_{B}\left(T_{i}, Q_{i}\right)>\pi_{B}\left(T_{j}, Q_{j}\right)$, then supplier $i$ wins the bidding game, and makes a profit of $T_{i}-C_{i}\left(Q_{i}\right)$. If $\pi_{B}\left(T_{i}, Q_{i}\right)<\pi_{B}\left(T_{j}, Q_{j}\right)$, then supplier $i$ loses, and makes a profit of $\Delta_{j}\left(\hat{q}_{i} ; Q_{j}\right)$. Note that this is the gain from subcontracting. If there is a tie, the buyer will choose the supplier that gives a higher supply chain profit.

Supplier $i$ 's objective is to maximize his profit by choosing $\left(T_{i}, Q_{i}\right)$, taking into account the subcontracting decision in the later stage. As opposed to the benchmark case without subcontracting, supplier $i$ 's reservation profit (when he loses) is positive (i.e., $\Delta_{j}\left(\hat{q}_{i} ; Q_{j}\right)>0$ ). We now characterize the equilibrium for suppliers as shown in Proposition 3.

Proposition 3 (Equilibrium with subcontracting). Suppose the losing supplier determines the subcontract, then:

(a) There exists a unique subgame perfect Nash equilibrium $\left\{\left(Q_{1}^{l}, T_{1}^{l}, \hat{q}_{2}^{l}, \hat{t}_{2}^{l}\right),\left(Q_{2}^{l}, T_{2}^{l}, \hat{q}_{1}^{l}, \hat{t}_{1}^{l}\right)\right\}$ where, for $i=1,2, j=3-i, Q_{i}^{l}=\bar{Q}_{i}, \hat{q}_{j}^{l}$ is obtained by solving $C_{i}^{\prime}\left(\bar{Q}_{i}-\hat{q}_{j}^{l}\right)=C_{j}^{\prime}\left(\hat{q}_{j}^{l}\right), T_{i}^{l}=C_{i}\left(\bar{Q}_{i}\right)+\max \left[\Pi_{i}+\right.$ $\left.\Delta_{i}\left(\hat{q}_{j}^{l} ; \bar{Q}_{i}\right)-\Pi_{j}, \Delta_{j}\left(\hat{q}_{i}^{l} ; \bar{Q}_{j}\right)\right]$, and $\hat{t}_{j}^{l}=C_{i}\left(\bar{Q}_{i}\right)-C_{i}\left(\bar{Q}_{i}-\hat{q}_{j}^{l}\right) ;$

(b) in equilibrium, each supplier $i$ 's profit is $\pi_{i}^{l}=\max \left[\Pi_{i}+\Delta_{i}\left(\hat{q}_{j}^{l} ; \bar{Q}_{i}\right)-\Pi_{j}, \Delta_{j}\left(\hat{q}_{i}^{l} ; \bar{Q}_{j}\right)\right]$, the buyer's profit is $\pi_{B}^{l}=\min \left[\Pi_{i}-\Delta_{j}\left(\hat{q}_{i}^{l} ; \bar{Q}_{j}\right), \Pi_{j}-\Delta_{i}\left(\hat{q}_{j}^{l} ; \bar{Q}_{i}\right)\right]$, and the supply chain profit is $\Pi^{l}=\max \left[\Pi_{i}+\right.$ $\left.\Delta_{i}\left(\hat{q}_{j}^{l} ; \bar{Q}_{i}\right), \Pi_{j}+\Delta_{j}\left(\hat{q}_{i}^{l} ; \bar{Q}_{j}\right)\right]$.

The proposition shows that if the subcontract is determined by the losing supplier of the bidding game, supplier $i$ will offer a bid with the quantity $Q_{i}^{l}=\bar{Q}_{i}$. Note that $\bar{Q}_{i}$ maximizes the supply chain profit when supplier $i$ is the sole supplier. If supplier $i$ wins the bidding game, he will subcontract 
$\hat{q}_{j}^{l}$ units to supplier $j$, and produce $\bar{Q}_{i}-\hat{q}_{j}^{l}$ himself. In equilibrium both suppliers produce a positive number of products, and the production amounts are allocated in a way that the suppliers' marginal costs are identical (i.e., $\left.C_{i}^{\prime}\left(\bar{Q}_{i}-\hat{q}_{j}^{l}\right)=C_{j}^{\prime}\left(\hat{q}_{j}^{l}\right)\right)$.

We also know from the above proposition that each supplier $i$ 's profit is no smaller than the reservation profit $\Delta_{j}\left(\hat{q}_{i}^{l} ; \bar{Q}_{j}\right)$, which is the gain from the subcontracting game. In equilibrium the buyer's profit is $\pi_{B}^{l}=\min \left[\Pi_{j}-\Delta_{i}\left(\hat{q}_{j}^{l} ; \bar{Q}_{i}\right), \Pi_{i}-\Delta_{j}\left(\hat{q}_{i}^{l} ; \bar{Q}_{j}\right)\right]$. As opposed to the case without subcontracting, the buyer's profit is smaller when subcontracting is considered. This suggests that a positive reservation profit (when losing the bidding game) makes suppliers compete less aggressively, because even when they lose the bidding game, they can still make a profit from subcontracting. In Section 6 , we will discuss in detail the impact of subcontracting on supplier bidding behaviors and the buyer's profit.

Example 4. Again we use Example 1 to illustrate the equilibrium for suppliers. From Proposition 3 we know the equilibrium strategies are given by $\left(T_{1}^{l}, Q_{1}^{l}\right)=(1 / 4,1 / 2)$ and $\left(T_{2}^{l}, Q_{2}^{l}\right)=$ $(11 / 72,1 / 3)$. In equilibrium the buyer will select supplier 1 . Then supplier 1 offers a subcontract $\left(\hat{t}_{2}^{l}, \hat{q}_{2}^{l}\right)=(5 / 72,1 / 6)$ to supplier 2 . As a result, supplier 1 produces $1 / 3$ units of the product and supplier 2 produces $1 / 6$ units. The equilibrium profit split is: $\pi_{1}^{l}=1 / 24, \pi_{2}^{l}=1 / 24$, and $\pi_{B}^{l}=5 / 24$. The supply chain profit is $\Pi^{l}=7 / 24$.

\section{Order Splitting}

Under the situation of order splitting, the buyer does not make a single-sourcing commitment so she may split the order between suppliers. In light of the nonlinear (convex) costs, we assume that each supplier submits a function bid, which specifies different payments for different quantities; see similar arrangements in the supply function equilibrium literature (Klemperer and Meyer 1989). Specifically, we assume each supplier $i$ 's strategy is chosen from $\mathbb{T}_{i}$ being the set of functions $T_{i}(q)$ satisfying: (a) $T_{i}^{\prime}(q)>0$ and $T_{i}^{\prime \prime}(q)>0$ for $q>0$; (b) $T_{i}(0)=0$ and we allow for a discontinuity at 0 ; (c) $T_{i}^{\prime}(q) \geq C_{i}^{\prime}(q)$ for $q>0$. First, supplier bids are increasing, convex, and twice differentiable everywhere except at the origin. Second, $T_{i}(0)=0$ reflects the fact that if supplier $i$ is not chosen, the buyer does not pay anything to him. We also allow the discontinuity at $q=0$. Finally, the suppliers - as rational players - do not set the marginal price below the marginal cost, so (b) and (c) together imply that $T_{i}(q) \geq C_{i}(q)$ for $q \geq 0$.

Following the backward induction approach, we start with the buyer's problem, and then characterize the equilibrium for suppliers.

\subsection{Buyer's problem}

Given the supplier bids $\left\{T_{1}(q), T_{2}(q)\right\}$, the buyer's problem is to maximize her profit by choosing the purchase amount from each supplier:

$$
\max \left\{\pi_{B}\left(q_{1}, q_{2}\right)=R\left(q_{1}+q_{2}\right)-T_{1}\left(q_{1}\right)-T_{2}\left(q_{2}\right): q_{1}, q_{2} \geq 0\right\} .
$$


Due to the possible discontinuity of $T_{i}(q)$ at $q=0$ where $i=1,2$, we consider two cases regarding the buyer's ordering decision: dual-sourcing, in which the buyer purchases from both suppliers, and single-sourcing, in which the buyer purchases from only one supplier.

If the buyer adopts the dual-sourcing strategy, the optimal solution $\left(q_{1}^{D}, q_{2}^{D}\right)$ must satisfy the conditions:

$$
R^{\prime}\left(q_{1}^{D}+q_{2}^{D}\right)=T_{1}^{\prime}\left(q_{1}^{D}\right)=T_{2}^{\prime}\left(q_{2}^{D}\right) .
$$

Let $\pi_{B}^{D}=\pi_{B}\left(q_{1}^{D}, q_{2}^{D}\right)$ be the buyer's dual-sourcing optimal profit. If the buyer single-sources from supplier $i$, her problem is $\max \left\{\pi_{B}^{i}(q)=R(q)-T_{i}(q): q \geq 0\right\}$, where $i=1,2$. The optimal solution $q_{i}^{S}$ can be found by solving the condition,

$$
R^{\prime}\left(q_{i}^{S}\right)=T_{i}^{\prime}\left(q_{i}^{S}\right)
$$

Let $\pi_{B}^{i}=\pi_{B}^{i}\left(q_{i}^{S}\right)$ be the buyer's optimal profit when purchasing from supplier $i$.

There are three local maxima for the buyer's choice, and the buyer will choose the sourcing strategy that gives her the largest profit, i.e., $\max \left(\pi_{B}^{D}, \pi_{B}^{1}, \pi_{B}^{2}\right)$. Note that the buyer's optimal choice may not be unique. Following Cachon and Kok (2010), we assume the buyer breaks ties in favor of purchasing from more suppliers. That is, if $\pi_{B}^{D}=\max \left(\pi_{B}^{1}, \pi_{B}^{2}\right)$, the buyer will purchase from both suppliers.

\subsection{Equilibrium Analysis}

In this section, we study the equilibrium for suppliers. We begin by investigating each supplier's best response in choosing an optimal function bid.

5.2.1. Suppliers' best responses Without loss of generality, we look at supplier $i$ 's optimal choice of $T_{i}(q)$ in response to supplier $j$ 's bid $T_{j}(q)$. Define the buyer's order quantity as $q_{j}^{S}$ if she purchases from supplier $j$ only, and accordingly the buyer's profit is denoted by $\pi_{B}^{j}$. When determining an optimal bid, suppliers need to take into account the buyer's optimal ordering decision. Anticipating the buyer's decision, supplier $i$ aims to maximize his profit by choosing $T_{i}(q)$ :

$$
\begin{aligned}
\max _{T_{i}(q) \in \mathbb{T}_{i}} & \pi_{i}\left(T_{i}(q)\right)=T_{i}\left(q_{i}^{*}\right)-C_{i}\left(q_{i}^{*}\right) \\
\text { s.t. } \quad\left(q_{i}^{*}, q_{j}^{*}\right) & =\arg \max \left\{\pi_{B}\left(q_{i}, q_{j}\right):=R\left(q_{i}+q_{j}\right)-T_{i}\left(q_{i}\right)-T_{j}\left(q_{j}\right): q_{i}, q_{j} \geq 0\right\},
\end{aligned}
$$

where the constraint concerns the buyer's optimization problem, and $\left(q_{i}^{*}, q_{j}^{*}\right)$ is short for $\left(q_{i}^{*}\left(T_{i}, T_{j}\right), q_{j}^{*}\left(T_{i}, T_{j}\right)\right)$, denoting her order quantities given the bids $T_{i}(q)$ and $T_{j}(q)$. As mentioned earlier, the problem faced by the suppliers and the buyer forms a Stackelberg game with multiple leaders, and thus the best response problem for each supplier involves bilevel optimization (Dempe 2002). This has greatly challenged the equilibrium analysis for suppliers. We first obtain the necessary conditions for supplier $i$ 's best response as shown in Lemma 1. 
Lemma 1. Given $T_{j}(q)$, suppose $\hat{T}_{i}(q)$ is optimal for supplier $i$, then $\pi_{B}\left(q_{i}^{*}\left(\hat{T}_{i}, T_{j}\right), q_{j}^{*}\left(\hat{T}_{i}, T_{j}\right)\right)=$ $\pi_{B}^{j}$ and,

(a) $\hat{T}_{i}^{\prime}\left(\bar{Q}_{i}\right)=C_{i}^{\prime}\left(\bar{Q}_{i}\right)$, if $q_{j}^{*}\left(\hat{T}_{i}, T_{j}\right)=0$; or

(b) $\hat{T}_{i}^{\prime}\left(q_{i}^{*}\left(\hat{T}_{i}, T_{j}\right)\right)=C_{i}^{\prime}\left(q_{i}^{*}\left(\hat{T}_{i}, T_{j}\right)\right)$ where $R^{\prime}\left(q_{i}^{*}\left(\hat{T}_{i}, T_{j}\right)+q_{j}^{*}\left(\hat{T}_{i}, T_{j}\right)\right)=C_{i}^{\prime}\left(q_{i}^{*}\left(\hat{T}_{i}, T_{j}\right)\right)=$ $T_{j}^{\prime}\left(q_{j}^{*}\left(\hat{T}_{i}, T_{j}\right)\right)$, if $q_{j}^{*}\left(\hat{T}_{i}, T_{j}\right)>0$.

Lemma 1 shows that for supplier $i$ 's best response, the buyer makes a profit equal to $\pi_{B}^{j}$, which is the buyer's profit when sourcing from supplier $j$ only. So supplier $i$ takes all the additional supply chain surplus when he joins the supply chain. It is achievable because: $(1) T_{i}^{\prime}(\cdot)$ and $T_{j}^{\prime}(\cdot)$ are well defined (except at zero), and (2) the order quantity depends on $T_{i}$ and $T_{j}$ only via their derivatives. In view of the buyer's optimal decision and $T_{j}(\cdot)$, supplier $i$ will set the value of $T_{i}(q)$ as high as possible (while keeping the slope unchanged). As a result, for an optimal solution $\hat{T}_{i}(q)$, the buyer's profit must equal $\pi_{B}^{j}$, i.e., $\pi_{B}\left(q_{i}^{*}\left(\hat{T}_{i}, T_{j}\right), q_{j}^{*}\left(\hat{T}_{i}, T_{j}\right)\right)=\pi_{B}^{j}$.

The above lemma also reveals that supplier $i$ essentially competes on how to share the buyer's demand with supplier $j$. Supplier $i$ can first decide his desired demand allocation, and then chooses the bid so that the buyer's optimal choice is indeed his desired order split. Because of the possible discontinuity at zero, supplier $i$ needs to consider both the case where the buyer chooses to purchase from him only (i.e., part (a)) and the case where the buyer splits her order (i.e., part (b)). As discussed earlier, supplier $i$ will extract all the surpluses and leave the buyer her reservation profit only. Thus, it is to supplier $i$ 's best interest to maximize the total surpluses. A necessary condition for the supplier $i$ 's optimal bid is that the derivative of $\hat{T}_{i}(\cdot)$ equals that of $C_{i}(\cdot)$ at the buyer's order quantity as shown in the lemma.

5.2.2. Equilibrium characterization A Nash equilibrium is a pair of bids $\left\{T_{i}^{*}(q), T_{j}^{*}(q)\right\}$, which are mutual best responses for each supplier. Let $\pi_{B}^{*}, \pi_{i}^{*}, \pi_{j}^{*}$ be the equilibrium profits of the buyer, supplier $i$, and supplier $j$, respectively. We have the following equilibrium result.

Proposition 4 (Equilibrium with order splitting). A pair of bids $\left\{T_{1}^{*}(q), T_{2}^{*}(q)\right\}$ is a Nash equilibrium if and only if, for $i=1,2$ and $j=3-i$,

(a) $T_{i}^{* \prime}\left(\bar{q}_{i}\right)=C_{i}^{\prime}\left(\bar{q}_{i}\right)$ and $T_{i}^{* \prime}\left(\bar{Q}_{i}\right)=C_{i}^{\prime}\left(\bar{Q}_{i}\right)$;

(b) $T_{i}^{*}\left(\bar{q}_{i}\right)=C_{i}\left(\bar{q}_{i}\right)+\Pi-\Pi_{j}$ and $T_{i}^{*}\left(\bar{Q}_{i}\right)=C_{i}\left(\bar{Q}_{i}\right)+\Pi-\Pi_{j}$.

In equilibrium, the buyer's optimal choice is first best, i.e., $\left(q_{i}^{*}, q_{j}^{*}\right)=\left(\bar{q}_{i}, \bar{q}_{j}\right)$, and the profit split amongst players is: $\pi_{B}^{*}=\Pi_{i}+\Pi_{j}-\Pi$ and $\pi_{i}^{*}=\Pi-\Pi_{j}$. The total supply chain profit is $\Pi^{*}=\Pi$.

Proposition 4 establishes the necessary and sufficient conditions for equilibrium bids. There are two critical points for each supplier $i$ 's bid, namely, $\left(\bar{q}_{i}, T_{i}^{*}\left(\bar{q}_{i}\right)\right)$ and $\left(\bar{Q}_{i}, T_{i}^{*}\left(\bar{Q}_{i}\right)\right)$. When choosing the bid, each supplier needs to reconcile the case in which the buyer purchases from both suppliers 
with the case in which the buyer purchases from him only. The condition (b) in Proposition 4 states that each supplier makes the same profit between these two cases. The condition (a) follows directly from Lemma 1, which gives the optimality conditions on the derivatives of supplier bids.

The sketch of the proof for Proposition 4 is as follows. It starts by showing that there exists no equilibrium where the buyer purchases from only one supplier. In equilibria where the buyer sources from both suppliers, the proof reveals that the buyer is indifferent between purchasing from only one supplier and purchasing from both suppliers. The intuition of this result is that: if the buyer's single-sourcing profit from a supplier is smaller, then the other supplier can slightly increase the bid price while making sure that the buyer's original dual-sourcing choice remains optimal. Hence, the buyer's profits of single-sourcing and dual-sourcing must be identical. According to the tiebreaking rule, the buyer will purchase from both suppliers. That is, the buyer's choice is first best in equilibrium, showing that suppliers self-coordinate to achieve the supply chain optimal outcome. The proposition further shows that the equilibrium profit split is a Vickrey-Clarke-Groves (VCG) result: Each supplier $i$ makes a profit that equals his marginal contribution to the supply chain system, and the buyer takes the remaining profit. The literature on VCG mechanisms concerns designing efficient mechanisms to elicit agents to truthfully reveal their private cost information, and the agents each are allocated a profit in proportion to their marginal contributions (Ausubel and Milgrom 2006). The distinction of our study is that we are interested in how suppliers compete with each other rather than designing a mechanism for a buyer, and each supplier is paid according to their bids.

The equilibrium bidding strategy is not unique, but all equilibria lead to the same profit split and the same buyer choice. Any bid $T_{i} \in \mathbb{T}_{i}$ that crosses the two points, $\left(\bar{q}_{i}, C_{i}\left(\bar{q}_{i}\right)+\Pi-\Pi_{j}\right)$ and $\left(\bar{Q}_{i}, C_{i}\left(\bar{Q}_{i}\right)+\Pi-\Pi_{j}\right)$, and has the slopes of $C_{i}^{\prime}\left(\bar{q}_{i}\right)$ and $C_{i}^{\prime}\left(\bar{Q}_{i}\right)$ at these two points can be an equilibrium strategy for supplier $i$. For example, the bids obtained by shifting up the cost functions by their marginal contributions form an equilibrium, where, for $i=1,2$ and $j=3-i, T_{i}^{*}(0)=0$ and $T_{i}^{*}(q)=C_{i}(q)+\Pi-\Pi_{j}$ for $q>0$. That is, suppliers each add a constant margin to their cost functions everywhere except at the origin. This bidding contract can be regarded as an extension of a two-part tariff contract to the situations where supplier costs exhibit diseconomies of scale.

ExAmPle 5. We return to Example 1 to illustrate the above equilibrium. We know the supply chain optimal choice is $\left(\bar{q}_{1}, \bar{q}_{2}\right)=(2 / 5,1 / 5)$, and the supply chain optimal profit is $\Pi=3 / 10$. For the single-sourcing supply chain problems, we have $\Pi_{1}=1 / 4 ; \Pi_{2}=1 / 6$, and $\bar{Q}_{1}=1 / 2 ; \bar{Q}_{2}=1 / 3$. The following strategies form an equilibrium: $T_{1}^{*}(0)=T_{2}^{*}(0)=0, T_{1}^{*}(q)=q^{2} / 2+2 / 15$ and $T_{2}^{*}(q)=$ $q^{2}+1 / 20$, for $q>0$. The buyer's choice in equilibrium is $\left(q_{1}^{*}, q_{2}^{*}\right)=(2 / 5,1 / 5)$, and the profit split is: $\pi_{1}^{*}=\Pi-\Pi_{2}=2 / 15, \pi_{2}^{*}=\Pi-\Pi_{1}=1 / 20$, and $\pi_{B}^{*}=\Pi-\pi_{1}^{*}-\pi_{2}^{*}=7 / 60$. The supply chain profit is $\Pi^{*}=\Pi=3 / 10$. 


\section{Impacts of Subcontracting, Commitment and Scale Diseconomies}

In this section, we answer the questions regarding the impacts of subcontracting and single-sourcing commitment on equilibrium outcomes, with an aim to develop insights into firms' sourcing practices. We also analyze the case where supplier costs are linear, and demonstrate the effect of scale diseconomies on equilibrium outcomes.

\subsection{Impact of subcontracting}

How does subsequent subcontracting affect supplier bidding strategies and the buyer's procurement performance? We now make a comparison between single-sourcing commitment without subcontracting and that with subcontracting.

Proposition 5. We have: (a) $\pi_{B}^{w}>\pi_{B}^{n}>\pi_{B}^{l}$; (b) $\pi_{i}^{w} \leq \pi_{i}^{n}<\pi_{i}^{l}$ for $i=1,2$; (c) $\Pi^{w}>\Pi^{l}>\Pi^{n}$.

Part (a) of Proposition 5 shows that when the winning supplier determines the subcontract, the buyer benefits from subcontracting in equilibrium (i.e., $\pi_{B}^{w}>\pi_{B}^{n}$ ), while when the losing supplier determines the subcontract, subcontracting hurts the buyer in equilibrium (i.e., $\pi_{B}^{l}<\pi_{B}^{n}$ ). Part (b), however, shows that the results are reversed for each supplier. Specifically, for the high-cost supplier, say $k \in\{1,2\}$, we have $\pi_{k}^{w}=\pi_{k}^{n}=0$, which is smaller than $\pi_{k}^{l}>0$. For the low-cost supplier $3-k$, we have $\pi_{3-k}^{w}<\pi_{3-k}^{n}<\pi_{3-k}^{l}$. From Part (c) we know the total supply chain profit is higher when subcontracting is possible; this is understandable because subcontracting makes production allocation more efficient and hence leads to a higher supply chain profit.

Conventional wisdom suggests that the availability of subsequent subcontracting may soften the competition between suppliers in the bidding game, and thus the buyer may be worse off in the case of subcontracting (Marion 2015). In contrast, we find that, if the winning supplier offers the subcontract, the buyer may find subcontracting beneficial. We identify two driving forces of subcontracting that lead to this result: (1) the positive effect of efficiency improvement, which means that the buyer may gain a share of surpluses when the supply chain profit is improved; (2) the negative effect of reservation profit, which implies that a higher reservation profit will make suppliers bid less aggressively and thus hurt the buyer. The buyer's preference between subcontracting and non-subcontracting depends on which effect dominates the other. First consider the case when the winning supplier offers the subcontract. On the one hand, the supply chain profit is higher with subcontracting. This is the positive effect of subcontracting in terms of efficiency improvement. On the other hand, each supplier $i$ 's reservation profit (when he loses) is zero, whether or not subcontracting is considered. As a result, the efficiency improvement effects dominates the reservation profit effect, and thus the buyer becomes better off when subcontracting occurs. Next consider the case when the losing supplier offers the subcontract. We know that the supply chain profit is larger with subcontracting. However, the reservation profit of each supplier is positive 
(i.e., $\left.\Delta_{i}\left(\hat{q}_{j}^{l} ; Q_{i}\right)>0\right)$. Taken together, we find the negative effect of reservation profit outweighs the positive effect of efficiency improvement, so the buyer is worse off when subcontracting is considered.

Whether the winning or losing supplier determines the subcontract represents the two polar cases of bargaining power split in subcontracting. The player who determines the subcontract has high bargaining power. The above result suggests that the bargaining power split in subcontracting negotiation plays an important role in determining the impact of subcontracting on supplier bidding. Specifically, Proposition 5 suggests that, with a higher bargaining power for the winning supplier, each supplier bids a higher quantity, both the buyer's profit and the supply chain profit are larger, while each supplier's profit is smaller. The intuition is that, if the winning supplier's bargaining power in subcontracting becomes higher, the losing supplier's profit-making opportunity from subcontracting becomes smaller, while the winning supplier's profit becomes larger. As a result, suppliers bid more aggressively, anticipating that they can make more profits from subcontracting once they win. This also motivates suppliers to bid a higher quantity because of the subcontracting opportunity with the other supplier (i.e., $Q_{i}^{w}>Q_{i}^{n}$ ). Therefore, when the winning supplier enjoys higher bargaining power, in equilibrium each supplier becomes worse off, while the buyer is better off. The prisoner's dilemma in a dynamic game has been observed in other contexts. For example, Allaz and Vila (1993) show that, in a Cournot competition setting with forward markets, each firm sells forward in equilibrium, but is worse off than if the forward market does not exist.

\subsection{Impact of single-sourcing commitment}

What is the impact of single-sourcing commitment? In this section, we make the comparison between order splitting and single-sourcing commitment according to each player's equilibrium profit. Proposition 6 summarizes the results.

Proposition 6. We have: (a) $\pi_{B}^{n}>\pi_{B}^{*}, \pi_{i}^{n}<\pi_{i}^{*}, \Pi^{n}<\Pi^{*}$; (b) $\pi_{B}^{w}>\pi_{B}^{l}>\pi_{B}^{*}, \pi_{i}^{w}<\pi_{i}^{l}<\pi_{i}^{*}$, $\Pi^{l}<\Pi^{w}=\Pi^{*}$.

Overall, the above proposition reveals that single-sourcing commitment outperforms order splitting from the buyer's perspective, while the reverse is true from the suppliers' perspective, whether or not subcontracting is considered. The intuitive reason the buyer is better off under a singlesourcing commitment without subcontracting, as opposed to order splitting, is relatively straightforward. If the buyer does not commit to single-sourcing, suppliers may feel "assured" that they will win at least part of the buyer's business. The result suggests that this "assurance" softens the competition between suppliers. As a result, the buyer prefers to make a single-sourcing commitment. 
The comparison between order splitting and single-sourcing commitment with subcontracting is less intuitive. Under order splitting, the buyer directly purchases from both suppliers, while under single-sourcing commitment, the losing supplier does not contract with the buyer directly, but signs the subcontract with the winning supplier later. It implies that, under single-sourcing commitment, the assurance of getting some production jobs is postponed until the subcontracting stage. Our results suggest that, in this case, suppliers compete more aggressively in the bidding game. As a result, the buyer is better off making a commitment, while each supplier becomes worse off with commitment.

Proposition 6 suggests that single-sourcing is always better from the buyer's perspective. Some cautions are worth mentioning here. The existing literature on sourcing strategies has been focused on the buyer's decision after they receive contracts from suppliers, and there may be a number of factors that affect a buyer's choice between single-sourcing and multi-sourcing (Talluri et al. 2013). Admittedly, this paper does not capture every one of these factors. Instead, our model focuses on costs, and singles out the effects of subcontracting and single-sourcing commitment on supplier competition under diseconomies of scale. The key message from the proposition is that by committing to single-sourcing, the competition between suppliers will be intensified. As a consequence, the buyer may find it beneficial to make this commitment even when suppliers' costs exhibit diseconomies of scale.

\subsection{Impact of Scale Diseconomies}

So far our model has focused on the case where suppliers face diseconomies of scale. To analyze the impact of this assumption, we now consider the case where suppliers have linear costs. Suppose the cost functions are $C_{i}(q)=c_{i} q$ where $c_{i}$ is supplier $i$ 's unit cost, and all the other parameters remain the same as in the baseline model. Without loss of generality we assume $c_{1} \leq c_{2}$, which implies that supplier 1 has cost advantages (in a weak sense). Whenever there is no confusion we will continue to use the previous notation system for the analysis. For example, $\Pi_{i}$ and $\bar{Q}_{i}$ respectively denote the optimal supply chain profit and quantity when supplier $i$ is the sole supplier. Recall that $\bar{Q}_{i}$ is obtained by solving the equation $R^{\prime}\left(\bar{Q}_{i}\right)=c_{i}$, and $\Pi_{i}=R\left(\bar{Q}_{i}\right)-c_{i} \bar{Q}_{i}$. With $c_{1} \leq c_{2}$ we can show that $\Pi_{1} \geq \Pi_{2}$ and $\bar{Q}_{1} \geq \bar{Q}_{2}$. In the case of linear costs, from the supply chain point of view, the buyer will purchase from the most cost-effective supplier only. Therefore, the order splitting scenario becomes trivial since the buyer will never split her order.

In what follows, we will focus our attention on single-sourcing commitment. As before, we will analyze three games under single-sourcing commitment, and then compare their equilibrium outcomes. Proposition 7 summarizes the outcomes for the case of linear costs. 
Proposition 7. Suppose suppliers have linear costs and $c_{1} \leq c_{2}$, we have the following results: for $i=1,2$ and $j=3-i$,

(a) under single-sourcing commitment without subcontracting, there exists a unique equilibrium $\left\{\left(T_{1}^{n}, Q_{1}^{n}\right),\left(T_{2}^{n}, Q_{2}^{n}\right)\right\}$, where $Q_{i}^{n}=\bar{Q}_{i}$ and $T_{i}^{n}=c_{i} \bar{Q}_{i}+\max \left(0, \Pi_{i}-\Pi_{j}\right)$; the buyer's profit is $\pi_{B}^{n}=\Pi_{2}$, each supplier $i$ 's profit is $\pi_{i}^{n}=\max \left(0, \Pi_{i}-\Pi_{j}\right)$, and the supply chain profit is $\Pi^{n}=\Pi_{1}$;

(b) under single-sourcing commitment with subcontracting where the winning supplier offers the subcontract, there exists a unique subgame perfect Nash equilibrium $\left\{\left(T_{1}^{w}, Q_{1}^{w}, \hat{t}_{2}^{w}, \hat{q}_{2}^{w}\right),\left(T_{2}^{w}, Q_{2}^{w}, \hat{t}_{1}^{w}, \hat{q}_{1}^{w}\right)\right\}$, where $Q_{i}^{w}=\bar{Q}_{1}, T_{i}^{w}=c_{1} \bar{Q}_{1}, \hat{t}_{j}^{w}=0$, and $\hat{q}_{j}^{w}=0$; the buyer's profit is $\pi_{B}^{w}=\Pi_{1}$, each supplier $i$ 's profit is $\pi_{i}^{w}=0$, and the supply chain profit is $\Pi^{w}=\Pi_{1}$;

(c) under single-sourcing commitment with subcontracting where the losing supplier offers the subcontract, there exists a unique subgame perfect Nash equilibrium $\left\{\left(T_{1}^{l}, Q_{1}^{l}, \hat{t}_{2}^{l}, \hat{q}_{2}^{l}\right),\left(T_{2}^{l}, Q_{2}^{l}, \hat{t}_{1}^{l}, \hat{q}_{1}^{l}\right)\right\}$, where $Q_{i}^{l}=\bar{Q}_{i}, T_{i}^{l}=c_{i} \bar{Q}_{i}+\max \left(0, \Pi_{i}-\Pi_{j}\right), \hat{t}_{j}^{l}=0$, and $\hat{q}_{j}^{l}=0$; the buyer's profit is $\pi_{B}^{l}=\Pi_{2}$, each supplier $i$ 's profit is $\pi_{i}^{l}=\max \left(0, \Pi_{i}-\Pi_{j}\right)$, and the supply chain profit is $\Pi^{l}=\Pi_{1}$;

(d) $\pi_{B}^{w}>\pi_{B}^{l}=\pi_{B}^{n}, \pi_{i}^{w} \leq \pi_{i}^{l}=\pi_{i}^{n}$, and $\Pi^{w}=\Pi^{l}=\Pi^{n}$.

Part (a) to Part (c) characterize the equilibria for suppliers under the three cases of singlesourcing commitment. We observe from Part (a) and Part (c) that, when the losing supplier offers a subcontract in the subcontracting game, single-sourcing commitment with subcontracting reduces to single-sourcing commitment without subcontracting (i.e., the equilibrium outcomes in these two cases are the same). In equilibrium, supplier 1 wins the bidding game, the buyer's profit is $\Pi_{2}$, supplier 1's profit is $\Pi_{1}-\Pi_{2}$, and supplier 2's profit is 0 . Part (b) demonstrates that, in the case where the winning supplier offers the subcontract, both suppliers offer the same bid $\left(c_{1} \bar{Q}_{1}, \bar{Q}_{1}\right)$. In line with Proposition 2, the existence of subcontracting smooths out the cost asymmetry between suppliers, and leads to a head-to-head competition. In equilibrium the buyer takes all the supply chain profit $\Pi_{1}$, and both suppliers end up with zero profits.

Another observation from Proposition 7 is that subcontracting never occurs even though subcontracting is allowed. This is because in equilibrium the supplier with the lower cost always wins the bidding game, and there is no benefit of subcontracting to the winning supplier. As a result, only the low-cost supplier produces for the buyer's order. This result is in contrast to that with diseconomies of scale where both suppliers will produce a positive amount of the product.

Part (d) of the proposition shows that in situations with linear costs, the buyer benefits from subcontracting when the subcontract is determined by the winning supplier of the bidding game, while she is indifferent when the subcontract is determined by the losing supplier. When the winning supplier determines the subcontract, the subcontracting option allows the cost-disadvantaged supplier to subcontract the production job to the cost-advantaged supplier. This makes the costdisadvantaged supplier bid more aggressively. Since the cost-advantaged supplier has to react in 
a similar manner, in equilibrium the possibility of subcontracting makes both suppliers worse off, while the buyer becomes better off. This driving force, however, vanishes when the subcontract is determined by the losing supplier, and subcontracting option does not play a role in suppliers' bidding strategies.

The above result is in contrast with Proposition 5 where subcontracting may benefit or hurt the buyer. In particular, Proposition 5 shows that, when the subcontract is determined by the losing supplier, the buyer becomes worse off. This highlights the important role played by diseconomies of scale in determining the equilibrium outcomes. Due to diseconomies of scale, subcontracting improves the supply chain profit, but at the same time, increases suppliers' reservation profits. Our results show that the negative effect of increasing reservation profits outweighs the positive effect of efficiency improvement. In the case of linear costs, however, each supplier's reservation profit remains the same as that without subcontracting. Moreover, subcontracting does not improve the supply chain profit. Consequently, equilibrium outcomes will not be affected by subcontracting. Such discrepancy is largely attributed to the fact that subcontracting will never occur in the case of linear costs because it is always the cost-advantaged supplier that wins the bidding game. Even though subcontracting is allowed, subcontracting option becomes irrelevant.

\section{Concluding Remarks}

This paper studies supply contract competition under diseconomies of scale by considering singlesourcing commitment and subcontracting. In the first model, the buyer commits to purchasing from only one supplier. In this case, we study the impact of subsequent subcontracting on suppliers' competitive bahaviors. The analysis shows that the buyer benefits from subcontracting when the winning supplier determines the subcontract. The second model is the order-splitting scenario, in which the buyer does not make a single-sourcing commitment. We find that, in equilibrium, the buyer's optimal choice is always supply chain optimal. Each supplier's profit equals its marginal contribution to the supply chain system, and the buyer takes the remaining profit. By comparing the two models, we find that the buyer prefers to commit to single-sourcing. This result is robust to situations where there is a positive managerial cost of dealing with suppliers. If the administrative cost is taken into account, the buyer will have an even greater preference for single-sourcing commitment.

We believe the above results may offer some implications for procurement practices. Based on these results, our recommendation for procurement practitioners is to commit to single-sourcing prior to running a bidding process. For example, they could announce to suppliers in the Request for Quotations (RFQs) that the order will not be divided. Such commitment will eliminate the supplier's assurance of getting some businesses from the buyer. Therefore, it intensifies the competition between suppliers, which will benefit the buyer. In addition, our study suggests that it is 
important for buyers to better understand the subcontract market in which their suppliers participate (i.e., who determines the subcontract). Specifically, the suppliers' bargaining power split in subcontracting affects their bidding behaviors and the buyer's procurement performance. In practice, it may be difficult for the buyer to identify the bargaining power split in subcontracting negotiations between the winning and the losing suppliers. A rule of thumb is to consider how concentrated the subcontracting market is. For example, if there are few other subcontractors in the market, the losing supplier (as a subcontractor) may have high bargaining power. In this case, subcontracting might be detrimental for the buyer.

In our paper, we assume suppliers know each other's cost but the buyer does not know supplier costs. This fits some settings better than the others. An interesting extension of the paper is to examine the incomplete information setting in which suppliers each have private information regarding their own costs. This extension certainly enriches our model, but will also present significant challenges because it involves solving a Bayesian Nash equilibrium for suppliers with nonlinear costs. We leave this extension for future research.

\section{Acknowledgement}

I would like to thank the Editor, the anonymous Senior Editor, Associate Editor and referees for their quality reviews, which have greatly improved this paper. I am also grateful to Professor Eddie Anderson for his constructive comments on early versions of this paper.

\section{References}

Blaise Allaz and Jean-Luc Vila. Cournot competition, forward markets and efficiency. Journal of Economic Theory, 59(1):1-16, 1993.

James J. Anton and Dennis A. Yao. Split awards, procurement, and innovation. The RAND Journal of Economics, 20(4):538-552, 1989 .

James J. Anton and Dennis A. Yao. Coordination in split award auctions. The Quarterly Journal of Economics, 107(2):681-707, 1992.

Alper Atamturk and Dorit S. Hochbaum. Capacity acquisition, subcontracting, and lot sizing. Management Science, 47(8):1081-1100, 2001.

Lawrence M. Ausubel and Paul Milgrom. The lovely but lonely Vickrey Auction. In Peter Cramton, Yoav Shoham, and Richard Steinberg, editors, Combinatorial Auctions, pages 22-26. MIT Press, 2006.

Volodymyr Babich, Apostolos N. Burnetas, and Peter H. Ritchken. Competition and diversification effects in supply chains with supplier default risk. Manufacturing $\&$ Service Operations Management, 9(2): $123-146,2007$.

Ross Baldick, Ryan Grant, and Edward Kahn. Theory and application of linear supply function equilibrium in electricity markets. Journal of Regulatory Economics, 25(2):143-167, 032004. 
B. Douglas Bernheim and Michael D. Whinston. Menu auctions, resource allocation, and economic influence. The Quarterly Journal of Economics, 101(1):1-32, 1986.

Fernando Bernstein, Changrong Deng, and Sasa Pekec. Single versus multiple sourcing: Drivers of supplier diversification. Duke University Working Paper, 2013.

Gerard J. Burke, Janice E. Carrillo, and Asoo J. Vakharia. Single versus multiple supplier sourcing strategies. European Journal of Operational Research, 182(1):95 - 112, 2007.

Gerard P. Cachon. Supply chain coordination with contracts. In Graves S. F. and de Kok de, editors, Handbooks in operations research and management science: Supply chain management, chapter 7, pages 229-339. North Holland, Amsterdam, The Netherlands, 2003.

Gerard P. Cachon and A. Gurhan Kok. Competing manufacturers in a retail supply chain: On contractual form and coordination. Management Science, 56(3):571-589, 2010.

Jim Carbone. Sun's e-auction evolution. http://www.purchasing.com/article/CA6474837.html, September 2007. Purchasing News.

Fangruo Chen. Auctioning supply contracts. Management Science, 53(10):1562-1576, 2007.

Sudipto Dasgupta and Daniel F. Spulber. Managing procurement auctions. Information Economics and Policy, 4(1):5-29, 1989.

Stephan Dempe. Foundations of Bilevel Programming. Nonconvex Optimization and Its Applications. Springer US, 2002.

Wedad J. Elmaghraby. Supply contract competition and sourcing policies. Manufacturing $\&$ Service Operations Management, 2(4):350-371, 2000.

Guillermo Gallego and Masoud Talebian. Commissions and sales targets under competition. Management Science, 60(9):2180-2197, 2014.

Albert. Y. Ha, Shilu Tong, and Hongtao Zhang. Sharing demand information in competing supply chains with production diseconomies. Management Science, 57(3):566-581, 2011.

IBIS. Commercial cleaning services in Australia. http://www.ibisworld.com.au/industry/default.aspx?indid=574, May 2014. IBIS Worldwide.

Morton I. Kamien, Lode Li, and Dov Samet. Bertrand competition with subcontracting. The RAND Journal of Economics, 20(4):553-567, 1989.

Saravanan Kesavan and Vidya Mani. An overview of industry practice and empirical research in retail workforce management. In Narendra Agrawal and Stephen A. Smith, editors, Retail Supply Chain Management: Quantitative Models and Empirical Studies, chapter 6, pages 113-145. Springer, New York, 2015.

Paul D. Klemperer and Margaret A. Meyer. Supply function equilibria in oligopoly under uncertainty. Econometrica, 57(6):1243-77, 1989. 
Tripti Lahiri and Christina Passariello. Why retailers don’t know who sews their clothing. The Wall Street Journal, July 2013.

Martin A. Lariviere. Supply chain contracting and coordination with stochastic demand. In Sridhar Tayur, Ram Ganeshan, and Michael Magazine, editors, Quantitative Models for Supply Chain Management, pages 233-268. Springer US, 1999.

Meng Li, Nicholas C. Petruzzi, and Jun Zhang. Overconfident competing newsvendors. Management Science, forthcoming, 2016.

Pranab Majumder and Ashok Srinivasan. Leadership and competition in network supply chains. Management Science, 54(6):1189-1204, 2008.

Justin Marion. Sourcing from the enemy: Horizontal subcontracting in highway procurement. The Journal of Industrial Economics, 63(1):100-128, 2015.

Victor Martínez-de Albéniz and David Simchi-Levi. Competition in the supply option market. Operations Research, 57(5):1082-1097, 2009.

Andre Varella Mollick. Production smoothing in the Japanese vehicle industry. International Journal of Production Economics, 91(1):63-74, 2004.

Dilip Mookherjee. Decentralization, hierarchies, and incentives: A mechanism design perspective. Journal of Economic Literature, 44(2):367-390, 2006.

Mahesh Nagarajan and Greys Sosic. Stable farsighted coalitions in competitive markets. Management Science, 53(1):29-45, 2007.

Mahesh Nagarajan and Greys Sosic. Game-theoretic analysis of cooperation among supply chain agents: Review and extensions. European Journal of Operational Research, 187(3):719-745, 2008.

Steve Norton. Maersk takes procurement to the cloud. http://www.wsj.com/articles/maersk-takesprocurement-to-the-cloud-1431722545, May 2015.

Nils Rudi, Sandeep Kapur, and David F. Pyke. A two-location inventory model with transshipment and local decision making. Management Science, 47(12):1668-1680, 2001.

Leo K Simon and William R Zame. Discontinuous Games and Endogenous Sharing Rules. Econometrica, 58(4):861-72, July 1990.

Srinivas Talluri, Hugo A. DeCampos, and G. Tomas M. Hult. Supplier rationalization: A sourcing decision model. Decision Sciences, 44(1):57-86, 2013.

Srinivas Talluri and Ram Narasimhan. A methodology for strategic sourcing. European Journal of Operational Research, 154(1):236-250, 2004.

Jean Tirole. The Theory of Industrial Organization. MIT Press, 1988.

Tunay I. Tunca and Qiong Wu. Multiple sourcing and procurement process selection with bidding events. Management Science, 55(5):763-780, 2009. 
Mericcan Usta, Feryal Erhun, and Warren H. Hausman. Buyer-induced supplier collaboration through commitment to low prices and diversified sourcing. SSRN eLibrary, 2015.

Gijsbert Van Liemt. Subcontracting in electronics: From contract manufacturers to providers of Electronic Manufacturing Services (EMS). Sectoral Activities Programme, Working Paper, (249), 2007.

Jan A. Van Mieghem. Coordinating investment, production, and subcontracting. Management Science, 45 (7):954-971, 1999.

Dong J. Wu and Paul R. Kleindorfer. Competitive options, supply contracting, and electronic markets. Management Science, 51(3):452-466, 2005.

Elisabeth Wynhausen. Cleaning industry's dirty secrets. http://www.theaustralian.com.au/archive/lifestyle/cleaningindustrys-dirty-secrets.html, October 2008. The Australian.

Hui Zhao, Vinayak Deshpande, and Jennifer K. Ryan. Inventory sharing and rationing in decentralized dealer networks. Management Science, 51(4):531-547, 2005. 
Table 1 The summary of key symbols

\begin{tabular}{|c|c|}
\hline Notation & Interpretation \\
\hline $\bar{Q}$ & Supply chain optimal total quantity \\
\hline $\bar{q}_{i}$ & Supply chain optimal quantity from supplier $i$ \\
\hline $\bar{Q}_{i}$ & Single-sourcing supply chain optimal quantity from supplier $i$ \\
\hline$\Pi$ & Supply chain optimal profit \\
\hline$\Pi_{i}$ & Single-sourcing supply chain optimal profit from supplier $i$ \\
\hline$\overline{T_{i}^{n}}$ & Supplier $i$ 's bidding payment in equilibrium under SC-N \\
\hline$Q_{i}^{n}$ & Supplier $i$ 's bidding quantity in equilibrium under SC-N \\
\hline$\pi_{i}^{n}$ & Supplier $i$ 's profit in equilibrium under SC-N \\
\hline$\pi_{B}^{n}$ & Buyer's profit in equilibrium under SC-N \\
\hline$\Pi^{n}$ & Supply chain profit in equilibrium under SC-N \\
\hline$\hat{q}_{j}^{w}$ & Subcontracted amount if buyer chooses supplier $i$ in equilibrium under SC-W \\
\hline$\hat{t}_{j}^{w}$ & Subcontracting payment if the buyer chooses supplier $i$ in equilibrium under SC-W \\
\hline$T_{i}^{w}$ & Supplier $i$ 's bidding payment in equilibrium under SC-W \\
\hline$Q_{i}^{w}$ & Supplier $i$ 's bidding quantity in equilibrium under SC-W \\
\hline$\pi_{i}^{w}$ & Supplier $i$ 's profit in equilibrium under SC-W \\
\hline$\pi_{B}^{w}$ & Buyer's profit in equilibrium under SC-W \\
\hline$\Pi^{w}$ & Supply chain profit in equilibrium under SC-W \\
\hline$\hat{q}_{j}^{l}$ & Subcontracted amount if buyer chooses supplier $i$ in equilibrium under SC-L \\
\hline$\hat{t}_{j}^{l}$ & Subcontracting payment if the buyer chooses supplier $i$ in equilibrium under SC-L \\
\hline$T_{i}^{l}$ & Supplier $i$ 's bidding payment in equilibrium under SC-L \\
\hline$Q_{i}^{l}$ & Supplier $i$ 's bidding quantity in equilibrium under SC-L \\
\hline$\pi_{i}^{l}$ & Supplier $i$ 's profit in equilibrium under SC-L \\
\hline$\pi_{B}^{l}$ & Buyer's profit in equilibrium under SC-L \\
\hline$\Pi^{l}$ & Supply chain profit in equilibrium under SC-L \\
\hline$q_{i}^{D}$ & Dual-sourcing buyer's optimal order from supplier $i$ \\
\hline$q_{i}^{S}$ & Single-sourcing buyer's optimal order from supplier $i$ \\
\hline$\hat{q}_{i}^{*}$ & Buyer's optimal order from supplier $i$ when supplier $i$ offers at cost \\
\hline$\hat{q}_{j}^{*}$ & Buyer's optimal order from supplier $j$ when supplier $i$ offers at cost \\
\hline$\pi_{B}^{D}$ & Dual-sourcing buyer's optimal profit \\
\hline$\pi_{B}^{i}$ & Single-sourcing buyer's optimal profit for supplier $i$ \\
\hline$T_{i}^{*}(q)$ & Supplier $i$ 's bid in equilibrium under order splitting \\
\hline$q_{i}^{*}$ & Buyer's order from supplier $i$ in equilibrium under order splitting \\
\hline$\pi_{i}^{*}$ & Supplier $i$ 's profit in equilibrium under order splitting \\
\hline$\pi_{B}^{*}$ & Buyer's profit in equilibrium under order splitting \\
\hline$\Pi^{*}$ & Supply chain profit in equilibrium under order splitting \\
\hline
\end{tabular}




\section{University Library}

\section{- M M N E R VA A gateway to Melbourne's research publications}

Minerva Access is the Institutional Repository of The University of Melbourne

Author/s:

SHAO, L

Title:

Competition Under Diseconomies of Scale: The Role of Subcontracting and Single-sourcing Commitment

Date:

2018-02

Citation:

SHAO, L. (2018). Competition Under Diseconomies of Scale: The Role of Subcontracting and Single-sourcing Commitment. Decision Sciences, 49 (1), pp.154-179. https:// doi.org/10.1111/deci.12268.

Persistent Link:

http://hdl.handle.net/11343/123514 